\title{
Systemic inflammation and sepsis. Part II: Functional consequences of the storm
}

Juan B. Dartiguelongue, M.D. ${ }^{a, b, c}$

\begin{abstract}
No organ is exempt from sepsis-induced dysfunction. Sustained, uncontrolled inflammatory activity triggers a sequence of systemic mechanisms that tend to affect tissue and vascular homeostasis. This is boosted by the effect typical of microorganisms, which leads to severe functional consequences for the patient. A child's body is particularly sensitive to the effects of sepsis, partly due to the immaturity of several physiological variables. As a result, there is usually an early clinical impact associated with a greater severity.

Although several intricate mechanisms lead to organ dysfunction, and many of them have not been fully elucidated, knowing them facilitates the understanding of the clinical picture and allows to establish an adequate therapeutic approach for each specific case.

Key words: sepsis, septic shock, multiple organ failure.
\end{abstract}

a. Hospital de Niños Ricardo Gutiérrez, Autonomous City of Buenos Aires,

Argentina.

b. Department of Pediatrics, School of Medicine, Universidad de Buenos Aires, Argentina. Office at Hospital de Niños Ricardo Gutiérrez, Autonomous City of Buenos Aires, Argentina.

c. Argentine Society of Pediatrics, Autonomous City of Buenos Aires, Argentina.

E-mail address: Juan B. Dartiguelongue, M.D.:

jbdartiguelongue@ hotmail.com

Funding:

None.

Conflict of interest: None.

Received: 4-30-2020 Accepted: 7-23-2020 http: / / dx.doi.org/10.5546/aap.2021.eng.e1

To cite: Dartiguelongue JB. Systemic inflammation and sepsis. Part II: Functional consequences of the storm. Arch Argent Pediatr 2021;119(1):e1-e10.

\section{GLOSSARY}

ATP: adenosine triphosphate.

AVP: arginine vasopressin.

BNP: brain natriuretic peptide.

CRP: C-reactive protein.

DAMPs: damage-associated molecular patterns.

DIC: disseminated intravascular coagulation.

DNA: deoxyribonucleic acid.

HPA: hypothalamic-pituitary-adrenal.

ICAM-1: intercellular adhesion

molecule-1.

IL-1: interleukin 1.

IL-6: interleukin 6.

IL-18: interleukin 18.

MAP: mitogen-activated protein.

NF- $\kappa b$ : nuclear transcription factor

kappa-b.

NO: nitric oxide.
$\mathrm{O}_{2}$ : oxygen.

PAI-1: tissue plasminogen activator inhibitor-1.

PAMPs: pathogen-associated molecular patterns.

pSOFA: pediatric SOFA.

SOFA: Sequential Organ Failure

Assessment.

TFPI: tissue factor pathway inhibitor.

TLRs: Toll-like receptors.

TNF- $\alpha$ : tumor necrosis factor alpha.

\section{INTRODUCTION}

Organ dysfunction is the clinical presentation of sepsis and may go unnoticed in its initial stages. ${ }^{1}$ It is the consequence of tissue aggression mediated by the inflammatory storm and the causative microorganism. Endothelial damage, microvascular dysfunction, and cell metabolism alteration are the results of this process, whose final common pathway is progression to multiple organ failure. ${ }^{2-4}$ This implies cardiovascular, respiratory, renal, gastrointestinal, neuronal, and metabolic involvement, with severe functional consequences for the patient. ${ }^{5-7}$

The clinical and biological phenotype of sepsis may vary based on the following: age, environment, presence of an underlying disease, chronic medication use, recent surgeries, and the characteristics of the pathogenic microorganism itself. This often hinders the possibility of making a clinical diagnosis of organ dysfunction and sepsis. ${ }^{1}$

Although clinical scoring systems have not proven to be sensitive and specific enough to confirm the 
diagnosis of organ dysfunction in sepsis, the Sequential Organ Failure Assessment (SOFA), which takes into account clinical, hematologic, biochemical, and blood gas data, is highly useful to predict mortality in hospitalized patients with sepsis-induced organ dysfunction. ${ }^{1,8}$ Since this scoring system was initially developed for adults, ${ }^{9,10}$ in recent years, a pediatric version has been developed, known as pediatric SOFA ${ }^{11}$ (pSOFA) (Table 1). In this setting, sepsis is defined as an acute rise in the pSOFA score of 2 points or more (organ dysfunction) in patients with confirmed or suspected infection. ${ }^{11}$ In this scenario, overall mortality is almost $12 \% .{ }^{11}$

In pediatrics, the pSOFA should not be the only tool used to clinically define sepsis. Its use, which has been more widely disseminated across intensive care units, is supplemental, given that it should be considered together with other clinical scoring systems and does not replace clinical judgment or individual and institutional experience. ${ }^{1,11,12}$

Objective: To describe the mechanisms leading to organ dysfunction in sepsis.

\section{CELL INJURY}

This phenomenon precedes organ dysfunction. It is caused by the convergence of three main mechanisms: ischemia, cytopathic injury, and programmed cell death. Ischemia results from the combination of an endothelial injury, a loss of metabolic self-regulation (imbalance between oxygen $\left[\mathrm{O}_{2}\right]$ supply and demand), and microcirculatory alterations, caused by thrombosis and obstruction that reduce the $\mathrm{O}_{2}$ exchange area. ${ }^{13}$

A cytopathic injury is caused by the inability to use $\mathrm{O}_{2}$ to create energy. ${ }^{14}$ Tumor necrosis factor alpha (TNF- $\alpha$ ), nitric oxide (NO), and lipopolysaccharides bring about mitochondrial dysfunction due to the direct alteration of the electron transport chain, the degeneration of the mitochondrial ultrastructure (disruption and dysfunction of the proteins that make up the internal and external membranes), respiratory enzyme inhibition, oxidative stress, and mitochondrial deoxyribonucleic acid (DNA) break. ${ }^{15,16}$

Programmed cell death is caused by several mechanisms. Proinflammatory cytokines, lipopolysaccharides, and $\mathrm{O}_{2}$ free radicals cause apoptosis-related protein expression (Bad, Bax) and mitochondrial destruction. Both phenomena induce cytochrome $\mathrm{c}$ release into the cytoplasm, with the subsequent activation of intracellular caspases. ${ }^{17,18}$ Necroptosis and pyroptosis are proinflammatory forms of cell death. The former shares characteristics with necrosis and apoptosis, and takes place as an effect of TNF- $\alpha$ on intracellular caspase activation. ${ }^{19}$ On its side, pyroptosis is generated by the activation of intracellular caspase-1 in response to intracellular microorganism infection (Salmonella, etc.). It is characterized by cytokine release into the extracellular medium (inflammatory amplification), following which DNA fragmentation and cell lysis take place. ${ }^{20}$

\section{BLOOD, ENDOTHELIUM, AND MICROCIRCULATION}

Endothelial dysfunction implies a severe vascular homeostasis alteration. $\mathrm{O}_{2}$ free radicals, lytic enzymes, and other substances released by polymorphonuclear cells adhered to the vascular wall damage it and alter its function. This is boosted by the direct effect of lipopolysaccharides and proinflammatory cytokines (TNF- $\alpha$, interleukin 1 [IL-1], interleukin 6 [IL-6]). Therefore, the anticoagulant and antiadhesive properties of a healthy endothelium are lost, leading to an imbalance in favor of microvascular thrombosis, a loss of the barrier function, cell destruction, interstitial edema, and microcirculation alteration. ${ }^{13}$

\section{Hemostasis}

The mechanisms linked to hemostasis activation and control lose their usual regulation during sepsis. In the vascular endothelium, lipopolysaccharides, TNF- $\alpha$, and IL- 1 induce tissue factor expression, which initiates the extrinsic coagulation pathway. In addition, they reduce the expression of thrombomodulin (endothelial anticoagulant), heparan sulfate (physiological activator of antithrombin III), tissue plasminogen activator (thrombolysis initiator), and tissue factor pathway inhibitor (TFPI), while they increase tissue plasminogen activator inhibitor-1 (PAI-1) expression. ${ }^{21,22}$ This translates into a procoagulant and antifibrinolytic endothelial phenotype. 
Platelet recruitment occurs through binding to the exposed subendothelial extracellular matrix (directly and through bridges with the von Willebrand factor) and an increased endothelial adhesiveness, through the GPIIb / IIIa glycoprotein complex. ${ }^{23}$ The activation and consequent platelet aggregation favors the development of a prothrombotic state, which progresses to microvascular dysfunction.

Thrombocytopenia is a hematological marker of sepsis (Table 1). A marked thrombocytopenia $\left(<50000 / \mathrm{mm}^{3}\right)$ is associated with a worse prognosis. ${ }^{24,25}$ It is preceded by reduced fibrinolysis ${ }^{26}$ and results from platelet activation and consumption in the setting of a prothrombotic state in sepsis. Sustained platelet activation, together with the release of microparticles (platelet vesicles with cytokines and coagulation factors inside) and $\alpha$ - and $\delta$-granules, amplifies the inflammatory response and favors the development of endothelial dysfunction and multiple organ failure..$^{27-31}$

TABLE 1. Scoring system to define organ dysfunction and sepsis in pediatrics

\begin{tabular}{|c|c|c|c|c|c|}
\hline \multirow[t]{2}{*}{ Outcome measure } & \multicolumn{4}{|c|}{ Score } & \multirow[b]{2}{*}{4} \\
\hline & 0 & 1 & 2 & 3 & \\
\hline \multicolumn{6}{|l|}{ Respiratory } \\
\hline $\begin{array}{l}\mathrm{PaO}_{2} / \mathrm{FiO}_{2}{ }^{\mathrm{a}} \\
\text { or }\end{array}$ & $\geq 400$ & $300-399$ & 200-299 & $100-199^{*}$ & $<100^{*}$ \\
\hline $\mathrm{SpO}_{2} / \mathrm{FiO}_{2}^{\mathrm{b}}$ & $\geq 292$ & 264-291 & $221-264$ & $148-220^{*}$ & $<148^{*}$ \\
\hline \multicolumn{6}{|l|}{ Coagulation } \\
\hline Platelet count $\left(\times 10^{3} / \mathrm{mm}^{3}\right)$ & $>150$ & $100-149$ & $50-99$ & $20-49$ & $<20$ \\
\hline \multicolumn{6}{|l|}{ Hepatic } \\
\hline Bilirubin $(\mathrm{mg} / \mathrm{dL})$ & $<1.2$ & $1.2-1.9$ & $2.0-5.9$ & $6.0-11.9$ & $>12$ \\
\hline \multicolumn{6}{|l|}{$\begin{array}{l}\text { Cardiovascular } \\
\operatorname{MAP}(\mathrm{mmHg}) \text { or } \\
\text { inotropes }(\mu \mathrm{g} / \mathrm{kg} / \mathrm{min})^{c}\end{array}$} \\
\hline$<1 \mathrm{mo}$ & $\geq 46$ & $<46$ & Dopamine $\leq 5$ & Dopamine $>5$ & Dopamine $>15$ \\
\hline $1-11 \mathrm{mo}$ & $\geq 55$ & $<55$ & or & or & or \\
\hline $12-23 \mathrm{mo}$ & $\geq 60$ & $<60$ & dobutamine & epinephrine $\leq 0.1$ & epinephrine $>0.1$ \\
\hline $24-59 \mathrm{mo}$ & $\geq 62$ & $<62$ & & or & or \\
\hline $60-143$ mo & $\geq 65$ & $<65$ & & norepinephrine $\leq 0.1$ & norepinephrine $>0.1$ \\
\hline $144-216 \mathrm{mo}$ & $\geq 67$ & $<67$ & & & \\
\hline$>216 \mathrm{mo}^{\mathrm{d}}$ & $\geq 70$ & $<70$ & & & \\
\hline \multicolumn{6}{|l|}{ Neurologic } \\
\hline Pediatric Glasgow score & 15 & $13-14$ & $10-12$ & $6-9$ & $<6$ \\
\hline \multicolumn{6}{|l|}{ Renal } \\
\hline \multicolumn{6}{|l|}{ Creatinine $(\mathrm{mg} / \mathrm{dL})$} \\
\hline$<1 \mathrm{mo}$ & $<0.8$ & 0.8-0.9 & $1.0-1.1$ & $1.2-1.5$ & $\geq 1.6$ \\
\hline $1-11 \mathrm{mo}$ & $<0.3$ & $0.3-0.4$ & $0.5-0.7$ & $0.8-1.1$ & $\geq 1.2$ \\
\hline $12-23 \mathrm{mo}$ & $<0.4$ & $0.4-0.5$ & $0.6-1.0$ & $1.1-1.4$ & $\geq 1.5$ \\
\hline $24-59 \mathrm{mo}$ & $<0.6$ & $0.6-0.8$ & $0.9-1.5$ & $1.6-2.2$ & $\geq 2.3$ \\
\hline $60-143 \mathrm{mo}$ & $<0.7$ & $0.7-1.0$ & $1.1-1.7$ & $1.8-2.5$ & $\geq 2.6$ \\
\hline $144-216 \mathrm{mo}$ & $<1.0$ & $1.0-1.6$ & $1.7-2.8$ & $2.9-4.1$ & $\geq 4.2$ \\
\hline$>216 \mathrm{mo}^{\mathrm{d}}$ & $<1.2$ & $1.2-1.9$ & $2.0-3.4$ & $3.5-4.9$ & $\geq 5.0$ \\
\hline
\end{tabular}

pSOFA: pediatric Sequential Organ Failure Assessment; $\mathrm{PaO}_{2}$ : arterial oxygen partial pressure; $\mathrm{FiO}_{2}$ : fraction of inspired oxygen; $\mathrm{SpO}_{2}$ : peripheral oxygen saturation; MAP: mean arterial pressure.

* With assisted mechanical ventilation.

${ }^{\text {a }} \mathrm{PaO}_{2}$ was measured in $\mathrm{mmHg}$.

${ }^{\mathrm{b}}$ Only $\mathrm{SpO}_{2}$ measurements of $97 \%$ or lower were used.

${ }^{\mathrm{c}} \mathrm{MAP}(\mathrm{mmHg})$ was used for scores 0 and 1 . Inotropes $(\mu \mathrm{g} / \mathrm{kg} / \mathrm{min})$ were used for scores 2 to 4 .

${ }^{\mathrm{d}}$ The cutoff point for patients older than 18 years (216 months) was identical to the original SOFA score.

Source: modified from Matics TJ, Sanchez-Pinto N. Adaptation and Validation of a Pediatric Sequential Organ Failure

Assessment Score and Evaluation of the Sepsis-3 Definitions in Critically Ill Children. JAMA Pediatr. 2017;171(10):e172352. 
Disseminated intravascular coagulation (DIC) is the consequence of an uncontrolled coagulation cascade activation, which leads to factor consumption and microvascular thrombosis development. ${ }^{32}$ Neonates and infants younger than 6 months have a higher risk for bleeding during DIC ${ }^{32}$ because they have lower circulating levels of vitamin-K-dependent factors (II, VII, IX, and X). In turn, they have a lower ability to produce thrombin and reduced levels of natural coagulation inhibitors. Such differences explain the higher mortality due to DIC in this age group compared to older children and adults. ${ }^{33,34}$

\section{Hemorheology}

Both due to their mechanical properties and their abundance, red blood cells are the main determinants of blood's rheological behavior. When blood flow becomes slower in microcirculation, erythrocyte aggregation produces an increased resistance to flow due to a greater viscosity (thixotropy). ${ }^{35}$ Normally, erythrocyte aggregation occurs when plasma macromolecules, mainly fibrinogen, form bridges of electrostatic attraction among these cells. In addition, it depends on red blood cell rigidity and deformability properties, which may be modified based on their geometry (surface/ volume ratio), internal viscosity (hemoglobin function), and the membrane's elastic properties (adenosine triphosphate [ATP], lipid, and protein composition). ${ }^{36,37}$

In the case of sepsis, the changes in microcirculation imply the loss of functional capillary density, poor flow distribution and heterogeneity, microvascular reactivity alterations, glycocalyx degradation, and cell adherence to the endothelium..$^{38}$ Together with increased circulating fibrinogen and $\mathrm{O}_{2}$ free radical production (which increases erythrocyte rigidity due to a surface/volume ratio alteration), such changes promote pathological aggregation between erythrocytes, resistant to intravascular shear forces. This leads to a greater capillary obstruction, which invigorates microvascular dysfunction. ${ }^{39}$

\section{CARDIAC MUSCLE}

The extensive peripheral vascular involvement underscores myocardial function during sepsis so as to maintain $\mathrm{O}_{2}$ delivery to the tissues (Figure 1). However, myocardial dysfunction is very common ${ }^{40}$ and affects both systolic and diastolic function. ${ }^{41}$ It is the result of an intramyocardial inflammation triggered by several mechanisms. Cardiomyocytes express several Toll-like receptors (TLRs) on their membranes, which recognize and are activated by pathogen-associated molecular patterns (PAMPs) and damage-associated molecular patterns (DAMPs). Such interaction, through the intermediate activation of the nuclear transcription factor kappa-b (NF-kb) and intracellular kinases (mitogen-activated protein [MAP] kinases), depresses myocardial contractility. ${ }^{42}$ Specifically, this is caused by the activation of calpain, an intracellular protease that mediates contractile and structural protein destruction. ${ }^{43}$

Proinflammatory cytokines contribute to myocardial inflammation and dysfunction. Interleukin 18 (IL-18) induces the phosphorylation of the phospholamban-sarcoplasmic/ endoplasmic reticulum calcium ATPase (SERCA) system, an event leading to a reduced intracellular calcium bioavailability and, subsequently, reduced contractility. ${ }^{44}$ In turn, cardiomyocytes release proinflammatory cytokines and express intercellular adhesion molecule-1 (ICAM-1) in response to systemic inflammation. This allows the passage of leukocytes from coronary circulation which, together with ICAM-1 binding to molecules like fibrinogen, affects the actin cytoskeleton. As a consequence, there is a variation between cell depolarization and calcium release from the sarcoplasmic reticulum (excitation-contraction coupling), which reduces both contractility and relaxation. ${ }^{45-48}$ On its side, the activated coronary endothelium releases NO, which contributes to an altered contractile function, ${ }^{49}$ and the polymorphonuclear cells that invade the myocardial tissue produce $\mathrm{O}_{2}$ free radicals that harm intracellular organelles. The resulting mitochondrial dysfunction is supportive of ventricular contractile involvement. ${ }^{50}$

Such complex scenario implies, first of all, a contractile depression that affects both ventricles equally (Figure 1.B). The increase in heart rate initially offsets this phenomenon, maintaining a relatively constant minute volume. As a result, the cardiac muscle consumes more $\mathrm{O}_{2}$. During 
sepsis, the reduced tissue $\mathrm{O}_{2}$ extraction capacity causes myocardial ischemia, ${ }^{51,52}$ which affects even more contractile function and leads to ventricular rigidity which, in turn, affects diastolic function ${ }^{53}$ (Figures 1.C and D).

The circulating levels of biological markers of cardiovascular injury, like troponins $\mathrm{T}$ and I, have a high diagnostic correlation with sepsis severity and prognosis. ${ }^{54-56}$ The brain natriuretic peptide (BNP) and its precursor, pro-BNP, are released prematurely during sepsis due to the cell stretching that accompanies ventricular dysfunction and the action of proinflammatory molecules, including lipopolysaccharides, IL-1, and C-reactive protein (CRP). ${ }^{57-59}$ Their plasma levels are associated with myocardial dysfunction and are used in some clinical scoring systems to predict short-term mortality in sepsis. ${ }^{60,61}$

In newborns and infants, the cardiac muscle is particularly sensitive to the effects of sepsis. ${ }^{62}$

FIGURE 1. Representation of the cardiac cycle of the left ventricle through the pressure-volume loop in normal conditions and during sepsis

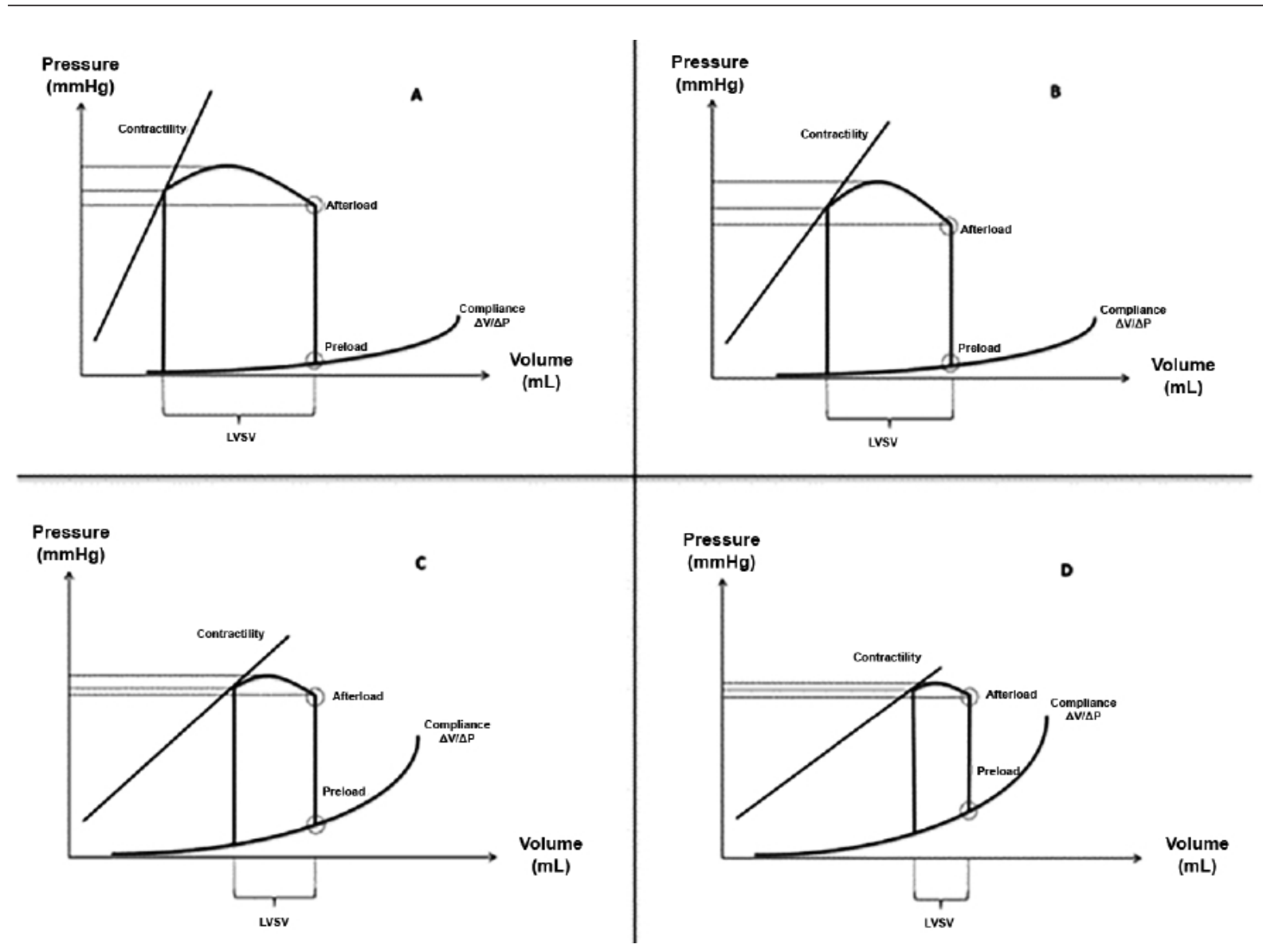

$\Delta \mathrm{P}$ : pressure difference; $\Delta \mathrm{V}$ : volume difference; LVSV: left ventricular systolic volume.

A: Normal left ventricle pressure-volume loop. B: In sepsis, myocardial involvement starts with a decreased ventricular contractility. This translates into a smaller slope in the contractility curve (end-systolic pressure/end-systolic volume). Therefore, LV systolic pressure decreases and, if preload does not change, so does the LVSV. The latter is partially buffered by the reduced afterload due to peripheral vasodilation, which takes place in the initial stages of sepsis.

C and D: As aggressive inflammation advances, myocardial contractility becomes progressively more affected, and this is associated with diastolic dysfunction due to an increased ventricular rigidity (greater slope of the compliance curve). LV systolic pressure continues decreasing, just like LVSV. Although preload increases, this mechanism does not lead to an increased LVSV because it is mainly the result of pressure gain (end-diastolic pressure elevation) and not of a higher diastolic filling. Note: Absolute volume and pressure values were not included due to the modifications resulting from age.

Source: Developed by the author. 
Contractile immaturity, a greater extracellular calcium dependence, a scarce response to diastolic filling (Frank-Starling mechanism), a smaller relaxation capacity, and an immature sympathetic innervation confer little functional reserve, ${ }^{62}$ which is associated with a worse prognosis and progression to septic shock. ${ }^{63}$

\section{LUNG}

The extensive pulmonary vascularization, in addition to the cardiac output that goes along with it, accounts for the high frequency of lung injury during sepsis. ${ }^{64}$ Endothelial injury and microvascular thrombosis and occlusion are responsible for the initial disruption of the alveolar-capillary barrier, which leads to the development of acute respiratory distress. ${ }^{64,65}$

Polymorphonuclear cell and platelet aggregation amplifies the local inflammatory response. ${ }^{66}$ Together with the direct action of microorganisms and proinflammatory cytokines, they cause cell death (necroptosis and pyroptosis), increased capillary permeability, surfactant loss, and interstitial and alveolar edema. The latter causes an intrapulmonary shunt that adds to the ventilation/perfusion alteration to induce hypoxemia. The severity of hypoxemia correlates to the severity of respiratory distress. ${ }^{11,67}$

The loss of alveolar surfactant increases superficial tension and lung elasticity. Therefore, the difference in pressure necessary to push the air volume is higher than normal. The resulting scarce alveolar recruitment, in addition to non-homogeneous ventilation caused by the coexistence of collapsed, ventilated alveoli with edema inside, leads to changes in lung tissue viscoelastic properties, and a greater resistance to air entry. Finally, the consecutive alveolar collapse and re-expansion and the resulting high difference in pressure amplify the alveolarcapillary barrier injury. ${ }^{68}$

Newborns and infants have a smaller capacity to placate respiratory aggression during sepsis. The horizontal orientation of ribs and the circular shape of the chest restrict the diaphragm to a rather horizontal position, thus hindering its contractile performance (lower transdiaphragmatic pressure). Likewise, type I muscle fibers (related to resistance to muscle fatigue) develop scarcely and the metabolic output from ventilatory effort is very high. ${ }^{68}$ This leads to an early respiratory muscle wasting.

\section{KIDNEY}

Renal involvement is associated with an increased mortality ${ }^{69}$ and is present in half of patients with sepsis. ${ }^{70}$ Acute kidney injury is the result of a combination between a lower renal perfusion and the aggressive inflammation of the parenchyma. ${ }^{69}$

Tubular necrosis and microvascular dysfunction are caused by an excessive vasoconstriction, the development of microthrombi in peritubular capillaries, polymorphonuclear cell infiltration, $\mathrm{O}_{2}$ free radical release, and direct action of proinflammatory cytokines and bacterial products, such as lipopolysaccharides and formylmethionineleucyl-phenylalanine (FMLP), a chemotactic tripeptide of the bacterial wall. This leads to a redistribution of blood flow to the renal medulla and the subsequent reduction in the glomerular filtration rate and a loss of fluid, electrolyte, and acid-base homeostasis. ${ }^{71}$

Although an increased level of serum creatinine is the standard method to define impairment of renal function, ${ }^{1,11}$ it occurs later than that of other markers. ${ }^{69}$ Plasma cystatin $\mathrm{C}$ and proenkephalin correlate just as well with kidney function and show an early elevation during sepsis. ${ }^{72-74}$

\section{LIVER AND DIGESTIVE TRACT}

Cholestatic liver dysfunction usually starts more insidiously than other types of dysfunction and is characterized by an increased level of bilirubin, alkaline phosphatase, and gammaglutamyl transferase. ${ }^{75}$ It is the result of an altered hepatobiliary transport induced by proinflammatory cytokines, $\mathrm{O}_{2}$ free radicals, and microvascular involvement. ${ }^{76,77}$

An alteration in intestinal microcirculation affects the digestive tract immune barrier. This favors bacterial translocation, thus amplifying the inflammatory response. In addition, the saprophytic flora and its defensive function become altered, which is associated with a greater mortality. ${ }^{78}$

\section{NERVOUS SYSTEM}

Brain dysfunction is caused by the diffuse alteration of neuronal metabolism and 
intercellular signaling. ${ }^{79}$ Proinflammatory cytokines reach the brain parenchyma through circumventricular organs and disruption of the blood-brain barrier. This causes brain inflammation, which implies the production of cytokines, $\mathrm{NO}$, prostaglandins, and $\mathrm{O}_{2}$ free radicals by neurons and glial cells. In addition to this, there is activated polymorphonuclear cell invasion and a direct lipopolysaccharide action, which, all together, affect central nervous system function. . $^{80,81}$

Thus, encephalopathy, which affects approximately half of patients with sepsis, presents with progressive depression of the sensorium, confusion, and lethargy, and usually precedes the other clinical manifestations of sepsis. ${ }^{79}$ Almost two-thirds of these patients develop critical illness polyneuropathy and myopathy in the following days or weeks. This occurs with generalized weakness and loss of thermoalgesic sensitivity. It usually lasts longer than encephalopathy and is associated with increased mortality. ${ }^{82,83}$

\section{NEUROENDOCRINE SYSTEM}

Neuroendocrine function may be affected by the direct action of proinflammatory cytokines (TNF- $\alpha$, IL-1, and IL-6) and bacterial products. ${ }^{84}$ It mainly occurs on the hypothalamic-pituitaryadrenal (HPA) axis and arginine vasopressin $(A V P)$. In addition, there is a tendency towards hyperglycemia (insulin resistance, counterregulation) and it may reduce thyroid function. The importance of neuroendocrine dysfunction contributes to other organ and system dysfunction, and is associated with a greater severity..$^{84,85}$

After an initial allostasis period, between $20 \%$ and $60 \%$ of patients with sepsis develop multifactorial HPA axis dysfunction. ${ }^{86,87}$ This leads to critical illness-related corticosteroid insufficiency, which is characterized by hemodynamic failure and progression to fluidand catecholamine-refractory septic shock..$^{86-89}$

AVP increases rapidly to supraphysiological values in the initial stages of sepsis (cytokines, lipopolysaccharides, hypovolemia) and decreases markedly during septic shock, thus affecting osmotic and cardiovascular homeostasis. ${ }^{90,91}$ Copeptin is released in equimolar amounts with
AVP following the fragmentation of its precursor (pro-AVP). AVP circulating levels increase during progression to septic shock, so it offers a high diagnostic correlation with sepsis severity and prognosis. ${ }^{92-95}$

\section{CONCLUSION}

The mechanisms leading to organ dysfunction in sepsis are various and intricate. Understanding them facilitates an early diagnosis and the choice of an adequate therapeutic approach.

\section{REFERENCES}

1. Singer M, Deutschman C, Seymour CW, Shankar-Hari M, et al. The Third International Consensus Definitions for Sepsis and Septic Shock (Sepsis-3). JAMA. 2016; 315(8):801-10.

2. Wiersinga WJ, Leopold SJ, Cranendonk DR, Van der Poll T. Host innate immune responses to sepsis. Virulence. 2014; 5(1):36-44.

3. Bateman S, Seed P. Procession to Pediatric Bacteremia and Sepsis: Covert Operations and Failures in Diplomacy. Pediatrics. 2010; 126(1):137-50.

4. Bone RC.Immunologic dissonance: a continuing evolution in our understanding of the systemicinflammatory response syndrome (SIRS) and the multiple organ dysfunction syndrome (MODS). Ann Intern Med. 1996; 125(8):680-7.

5. Hotchkiss RS, Monneret G, Payen D. Sepsis-induced immunosuppression: from cellular dysfunctions to immunotherapy. Nat Rev Immunol. 2013; 13(12):862-74.

6. Deutschman CS, Tracey KJ. Sepsis: current dogma and new perspectives. Immunity. 2014; 40(4):463-75.

7. Singer M, De Santis V, Vitale D, Jeffcoate W. Multiorgan failure is an adaptive, endocrine-mediated, metabolic response to overwhelming systemic inflammation. Lancet. 2004; 364(9433):545-8.

8. Seymour CW, Liu V, Iwashyna TJ, Brunkhorst F, et al. Assessment of clinical criteria for sepsis: For the Third International Consensus Definitions for Sepsis and Septic Shock (Sepsis-3). JAMA. 2016; 315(8):762-74.

9. Vincent JL, Moreno R, Takala J, Willatts S, et al. The SOFA (Sepsis-related Organ Failure Assessment) score to describe organ dysfunction/failure. On behalf of the Working Group on Sepsis-Related Problems of the European Society of Intensive Care Medicine. Intensive Care Med. 1996; 22(7):707-10.

10. Vincent JL, De Mendonça A, Cantraine F, Moreno R, et al. Use of the SOFA score to assess the incidence of organ dysfunction/failure in intensive care units: results of a multicenter, prospective study. Working group on "sepsisrelated problems" of the European Society of Intensive Care Medicine. Crit Care Med. 1998; 26(11):1793-800.

11. Matics TJ, Sanchez-Pinto LN. Adaptation and Validation of a Pediatric Sequential Organ Failure Assessment Score and Evaluation of the Sepsis-3 Definitions in Critically Ill Children. JAMA Pediatr. 2017; 171(10):e172352.

12. Kawasaki T. Update on pediatric sepsis: a review. Intensive Care. 2017; 5:47.

13. McGown CC, Brown NJ, Hellewell PG, Brookes ZL. ROCK induced inflammation of the microcirculation during endotoxemia mediated by nitric oxide synthase. Microvasc Res. 2011; 81(3):281-8. 
14. Brealey D, Brand M, Hargreaves I, Heales S, et al. Association between mitochondrial dysfunction and severity and outcome of septic shock. Lancet. 2002; 360(9328):219-23.

15. Harrois A, HuetO, DuranteauJ. Alterations of mitochondrial function in sepsis and critical illness. Curr Opin Anaesthesiol. 2009; 22(2):143-9.

16. Crouser ED, Julian MW, Blaho DV, Pfeiffer DR. Endotoxininduced mitochondrial damage correlates with impaired respiratory activity. Crit Care Med. 2002; 30(2):276-84.

17. Coopersmith CM, Stromberg PE, Dunne WM, Davis CG, et al. Inhibition of intestinal epithelial apoptosis and survival in a murine model of pneumonia-induced sepsis. JAMA. 2002; 287(13):1716-21.

18. Hotchkiss RS, Swanson PE, Freeman BD, Tinsley KW, et al. Apoptotic cell death in patients with sepsis, shock, and multiple organ dysfunction. Crit Care Med. 1999;27(7):123051.

19. Vanden Berghe T, Linkermann A, Jouan-Lanhouet $S$, WalczakH, etal. Regulated necrosis: theexpanding network of non-apoptotic cell death pathways. Nat Rev Mol Cell Biol. 2014; 15(2):135-47.

20. Jorgensen I, Miao EA. Pyroptotic cell death defends against intracellular pathogens. Immunol Rev. 2015; 265(1):130-42.

21. Peters K, Unger RE, Brunner J, Kirkpatrick J. Molecular basis of endothelial dysfunction in sepsis. Cardiovasc Res. 2003; 60(1):49-57.

22. Schouten M, Wiersinga WJ, Levi M, Van der Poll $\mathrm{T}$. Inflammation, endothelium, and coagulation in sepsis. J Leukoc Biol. 2008; 83(3):536-45.

23. Lorente JA, García-Frade LJ, Landín L, De Pablo R, et al. Time course of hemostatic abnormalities in sepsis and its relation to outcome. Chest. 1993; 103(5):1536-42.

24. Thiery-Antier N, Binquet C, Vinault S, Boisramé-Helms J, et al. Is Thrombocytopenia an Early Prognostic Marker in Septic Shock? Crit Care Med. 2016; 44(4):764-72.

25. Claushuis TAM, Van Vught LA, Scicluna BP, Wiewel MA, et al. Thrombocytopenia is associated with a dysregulated host response in critically ill sepsis patients. Blood. 2016; 127(24):3062-72.

26. Semeraro F, Colucci M, Ciaroni P, Masson S, et al. Platelet Drop and Fibrinolytic Shutdown in Patients With Sepsis. Crit Care Med. 2018; 46(3):e221-8.

27. Burnier L, Fontana P, Kwak BR, Angelillo-Scherrer A. Cell-derived microparticles in haemostasis and vascular medicine. Thromb Haemost. 2009; 101(3):439-51.

28. Tökés-Füzesi M, Woth G, Ernyey B, Vermes I, et al. Microparticles and acute renal dysfunction in septic patients. J Crit Care. 2013; 28(2):141-7.

29. Woth G, Tökés-Füzesi M, Magyarlaki T, Kovács GL, et al. Activated platelet-derived microparticle numbers are elevated in patients with severe fungal (Candida albicans) sepsis. Ann Clin Biochem. 2012; 49(Pt 6):554-60.

30. VincentJL, Yagushi A, Pradier O. Platelet function in sepsis. Crit Care Med. 2002; 30(5 Suppl):S313-7.

31. Hurley SM, Lutay N, Holmqvist B, Shannon O. The Dynamics of Platelet Activation during the Progression of Streptococcal Sepsis. PLoS One. 2016; 11(9):e0163531.

32. Levi M. Disseminated intravascular coagulation. Crit Care Med. 2007; 35(9):2191-5.

33. Kreuz W, Veldmann A, Fischer D, Schlösser R, et al. Neonatal sepsis: a challenge in hemostaseology. Semin Thromb Hemost. 1999; 25(6):531-5.

34. Veldman A, Fischer D, Nold MF, Wong FY. Disseminated intravascular coagulation in term and preterm neonates. Semin Thromb Hemost. 2010; 36(4):419-28.
35. Murata T. Theory of non-Newtonian viscosity of blood at low shear rate--effect of rouleaux. Biorheology. 1976; 13(5):287-96.

36. Rasia ML, Bazzoni GB, Hemorreología: comportamiento intrínseco del flujo sanguíneo. Rev Méd Rosario. 2003; 69(3):56-61.

37. Popel AS, Johnson PC. Microcirculation and hemorheology. Annu Rev Fluid Mech. 2005; 37:43-69.

38. Bateman RM, Sharpe MD, Ellis CG. Bench-to-bedside review:microvasculardysfunctioninsepsis-hemodynamics, oxygen transport, and nitricoxide. Crit Care. 2003;7(5):359-73.

39. Piagnarelli M, Zouaoui Boudjeltia K, Vanhaeberbeek M, Vincent JL. Red blood cell rheology in sepsis. Intensive Care Med. 2003; 29(7):1052-61.

40. Jain A, Sankar J, Anubhuti A, Yadav DK, et al. Prevalence and outcome of sepsis-induced myocardial dysfunction in children with 'sepsis' 'with' and 'without shock': prospective observational study. J Trop Pediatr. 2018; 64(6):501-9.

41. Walley KR. Sepsis-induced myocardial dysfunction. Curr Opin Crit Care. 2018; 24(4):292-9.

42. Boyd JH, Mathur S, Wang Y, Bateman RM, et al. Tolllike receptor stimulation in cardiomyoctes decreases contractility and initiates an NF-kappaB dependent inflammatory response. Cardiovasc Res. 2006; 72(3):384-93.

43. Freitas AC, Figueiredo MJ, Campos EC, Figueiredo D, et al. Activation of both the calpain and ubiquitin-proteasome systems contributes to septic cardiomyopathy through dystrophin loss/disruption and mTOR inhibition. PLoS One. 2016; 11(11):e0166839.

44. Okuhara Y, Yokoe S, Iwasaku T, Eguchi A, et al. Interleukin-18 gene deletion protects against sepsis-induced cardiac dysfunction by inhibiting PP2A activity. IntJ Cardiol. 2017; 243:396-403.

45. Davani EY, Boyd JH, Dorscheid DR, Wang Y, et al. Cardiac ICAM-1 mediates leukocyte-dependent decreased ventricular contractility in endotoxemic mice. Cardiovasc Res. 2006; 72(1):134-42.

46. Davani EY, Dorscheid DR, Lee CH, Van Breemen C, et al. Novel regulatory mechanism of cardiomyocyte contractility involving ICAM-1 and the cytoskeleton. Am J Physiol Heart Circ Physiol. 2004; 287(3):H1013-22.

47. Jianhui L, Rosenblatt-Velin N, Loukili N, Pacher P, et al. Endotoxin impairs cardiac hemodynamics by affecting loading conditions but not by reducing cardiac inotropism. Am J Physiol Heart Circ Physiol. 2010; 299(2):H492-501.

48. Boyd JH, Chau EH, Tokunanga C, Bateman RM, et al. Fibrinogen decreases cardiomyocyte contractility through an ICAM-1-dependent mechanism. Crit Care. 2008;12(1):R2.

49. Herbertson MJ, Werner HA, Walley KR. Nitric oxide synthase inhibition partially prevents decreased LV contractility during endotoxemia. Am J Physiol. 1996; 270(6 Pt 2):H1979-84.

50. Neviere R, Delguste F, Durand A, Inamo J, et al. Abnormal mitochondrial cAMP / PKA signaling is involved in sepsisinduced mitochondrial and myocardial dysfunction. Int J Mol Sci. 2016; 17(12):2075.

51. Herbertson MJ, Werner HA, Russell JA, Iversen K, et al. Myocardial oxygen extraction ratio is decreased during endotoxemia in pigs. J Appl Physiol (1985). 1995; 79(2):479-86.

52. Alders DJ, Groeneveld AB, Binsl TW, De Kanter FJ, et al. Endotoxemia decreases matching of regional blood flow and $\mathrm{O}_{2}$ delivery to $\mathrm{O}_{2}$ uptake in the porcine left ventricle. Am J Physiol Heart Circ Physiol. 2011; 300(4):H1459-66.

53. Sanfilippo F, Corredor C, Arcadipane A, Landesberg G, 
et al. Tissue doppler assessment of diastolic function and relationship with mortality in critically ill septic patients: a systematic review and meta-analysis. Br J Anaesth. 2017; 119(4):583-94.

54. Landesberg G, Jaffe AS, Gilon D, Levin PD, et al. Troponin elevation in severe sepsis and septic shock: the role of left ventricular diastolic dysfunction and right ventricular dilatation. Crit Care Med. 2014; 42(4):790-800.

55. Vallabhajosyula S, Sakhuja A, Geske JB, Kumar M, et al. Role of admission troponin-T and serial troponin- $T$ testing in predicting outcomes in severe sepsis and septic shock. J Am Heart Assoc. 2017; 6(9):e005930.

56. Bessière F, Khenifer S, Dubourg J, Durieu I, et al. Prognostic value of troponins in sepsis: a meta-analysis. Intensive Care Med. 2013; 39(7):1181-9.

57. Charpentier J, Luyt CE, Fulla Y, Vinsonneau C, et al. Brain natriuretic peptide: A marker of myocardial dysfunction and prognosis during severe sepsis. Crit Care Med. 2004; 32(3):660-5.

58. Post F, Weilemann LS, Messow CM, Sinning C, et al. B-type natriuretic peptide as a marker for sepsis-induced myocardial depression in intensive care patients. Crit Care Med. 2008; 36(11):3030-7.

59. Shor R, Rozenman Y, Bolshinsky A, Harpaz D, et al. BNP in septic patients without systolic myocardial dysfunction. Eur J Intern Med. 2006; 17(8):536-40.

60. Khoury J, Arow M, Elias A, MakhoulBF, etal. The prognostic value of brain natriuretic peptide (BNP) in non-cardiac patients with sepsis, ultra-long follow-up. J Crit Care. 2017; 42:117-22.

61. Ryoo SM, Kim WY, Huh JW, Hong SB, et al. Prognostic value of B-type natriuretic peptide with the sequential organ failure assessment score in septic shock. Am J Med Sci. 2015; 349(4):287-91.

62. DartiguelongueJB. Fisiología cardiovascular pediátrica. In Fisiología pediátrica aplicada a la clínica. Ciudad Autónoma de Buenos Aires: Journal; 2020.Págs.81-119.

63. Martin L, Derwall M, Zoubi SA, Zechendorf E, et al. The Septic Heart: Current Understanding of Molecular Mechanisms and Clinical Implications. Chest. 2019; 155(2):427-37.

64. Englert JA, Bobba C, Baron RM. Integrating molecular pathogenesis and clinical translation in sepsis-induced acute respiratory distress syndrome. JCI Insight. 2019; 4(2):e124061.

65. Stapleton RD, Wang BM, Hudson LD, Rubenfeld GD, et al. Causes and timing of death in patients with ARDS. Chest. 2005; 128(2):525-32.

66. Wohlrab P, Kraft F, Tretter V, Ullrich R, et al. Recent advances in understanding acute respiratory distress syndrome. F1000Res. 2018; 7:F1000.

67. Bellani G, Laffey JG, Pham T, Fan E, et al. Epidemiology, patterns of care, and mortality for patients with acute respiratory distress syndrome in intensive care units in 50 countries. JAMA. 2016; 315(8):788-800.

68. Dartiguelongue JB. Fisiología respiratoria pediátrica. In Fisiología pediátrica aplicada a la clínica. Ciudad Autónoma de Buenos Aires: Journal; 2020.Pages.121-54.

69. PostonJT, KoynerJL. Sepsis associated acutekidney injury. BMJ. 2019; 364:k4891.

70. Yegenaga I, Hoste E, Van Biesen W, Vanholder R, et al. Clinical characteristics of patients developing ARF due to sepsis/systemic inflammatory response syndrome: results of a prospective study. Am J Kidney Dis. 2004; 43(5):817-24.

71. Shum HP, Yan WW, Chan TM. Recent knowledge on the pathophysiology of septic acute kidney injury: A narrative review. J Crit Care. 2016; 31(1):82-9.

72. Kim H, Hur M, Lee S, Marino R, et al. Proenkephalin, NeutrophilGelatinase-Associated Lipocalin, and Estimated Glomerular Filtration Rates in Patients With Sepsis. Ann Lab Med. 2017; 37(5):388-97.

73. Mårtensson J, Martling CR, Oldner A, Bell M. Impact of sepsis on levels of plasma cystatin $\mathrm{C}$ in AKI and non-AKI patients. Nephrol Dial Transplant. 2012; 27(2):576-81.

74. Dai X, Zeng Z, Fu C, Zhang S, et al. Diagnostic value of neutrophil gelatinase-associated lipocalin, cystatin $C$, and soluble triggering receptor expressed on myeloid cells- 1 in critically ill patients with sepsis-associated acute kidney injury. Crit Care. 2015; 19(1):223.

75. Chand N, Sanyal AJ. Sepsis-induced cholestasis. Hepatology. 2007; 45(1):230-41.

76. Brienza N, Dalfino L, Cinnella G, Diele C, et al. Jaundice in critical illness: promoting factors of a concealed reality. Intensive Care Med. 2006; 32(2):267-74.

77. Jenniskens M, Langouche L, Vanwijngaerden YM, Mesotten D, et al. Cholestatic liver (dys)function during sepsis and other critical illnesses. Intensive Care Med. 2016; 42(1):16-27.

78. Hassoun HT, Kone BC, Mercer DW, Moody FG, et al. Postinjury multiple organ failure: the role of the gut. Shock. 2001; 15(1):1-10.

79. Helbing DL, Böhm L, Witte O. Sepsis-associated encephalopathy. CMAJ. 2018; 190(36):E1083.

80. Iacobone E, Bailly-Salin J, Polito A, Friedman D, et al. Sepsisassociated encephalopathy and its differential diagnosis. Crit Care Med. 2009; 37(10 Suppl):S331-6.

81. Flierl MA, Rittirsch D, Huber-Lang MS, Stahel PF. Pathophysiology of septic encephalopathy: an unsolved puzzle. Crit Care. 2010; 14(3):165.

82. Axer H, Grimm A, Pausch C, Teschner U, et al. The impairment of small nerve fibers in severe sepsis and septic shock. Crit Care. 2016; 20:64.

83. Shepherd S, Batra A, Lerner DP. Review of critical illness myopathy and neuropathy. Neurohospitalist. 2017; 7(1):418.

84. Gheorghiţă V, Barbu AE, Gheorghiu ML, Căruntu FA. Endocrine dysfunction in sepsis: a beneficial or deleterious host response? Germs. 2015; 5(1):17-25.

85. Sharshar T, Hopkinson NS, Orlikowski D, Annane D. Science review: The brain in sepsis - culprit and victim. Crit Care. 2005; 9(1):37-44.

86. Menon K, Ward RE, Lawson ML, Gaboury I, et al. A prospective multicenter study of adrenal functionin critically ill children. Am J Respir Crit Care Med. 2010; 182(2):246-51.

87. Cooper MS, Stewart PM. Corticosteroid insufficiency in acutely ill patients. N Engl J Med. 2003; 348(8):727-34.

88. Pizarro CF, Troster EJ, Damiani D, Carcillo JA. Absolute and relative adrenal insufficiency in children with septic shock. Crit Care Med. 2005; 33(4):855-9.

89. Karagüzel G, Cakir E. Adrenal dysfunction in critically ill children. Minerva Endocrinol. 2014; 39(4):235-43.

90. Russell JA. Bench-to-bedside review: Vasopressin in the management of septic shock. Crit Care. 2011; 15(4):226.

91. Demiselle J, Fage N, Radermacher P, Asfar P. Vasopressin and its analogues in shock states: a review. Ann Intensive Care. 2020; 10(1):9.

92. Latronico N, Castioni CA. Copeptin in critical illness. Clin Chem Lab Med. 2014; 52(10):1391-3.

93. StruckJ, Morgenthaler NG, Bergmann A. Copeptin, a stable peptide derived from the vasopressin precursor, is elevated in serum of sepsis patients. Peptides. 2005; 26(12):2500-4. 
e10 / Arch Argent Pediatr 2021;119(1):e1-e10 / Review

94. Palmiere C, Augsburger M. Copeptin as a diagnostic biomarker for sepsis-related deaths. Peptides. 2014; 59:75-8. 95. Morgenthaler NG, Müller B, Struck J, Bergmann A, et al.
Copeptin, a stable peptide of the arginine vasopressin precursor, is elevated in hemorrhagic and septic shock. Shock. 2007; 28(2):219-26. 